\title{
Recreational Games Program to Develop a Sense of Satisfaction with Life for People with Evening Personality
}

\author{
Salma Mohammed Abd El-Wahab Abu Hamar ${ }^{1}$ \\ ${ }^{1}$ Lecturer at the Sports Management \& Recreation Sports Department, Faculty of Physical Education, Tanta University, Egypt
}

\begin{abstract}
:
This research aims to develop a sense of satisfaction with the life of the evening personalities through the recreational games program and presented it to the experts in the field of recreation and psychology and Sociology on a sample of 30 students from the Faculty of Physical Education Tanta University, The program was applied for a period of (8) continuous weeks where the researcher to conduct the post and pre measurements by using a scale of satisfaction with the life for Magdy Mohamed Al-Desouki, morning and evening personal measure for Sara Allam, The researcher concluded that there were statistically significant differences between the mean of the post and pre measurements and the dimension measurements of the research group, The development of a sense of satisfaction for the life of the research sample for the pre measurement through recreational games program, and this improvement is due to the recreational games program with a positive impact by $69.41 \%$.
\end{abstract}

Keywords: Recreation games - Satisfaction with life - Evening Personality.

Introduction and Research Problem:

ince ancient times people believe that sleeping early and starting work early in the day is a welcome and virtuous approach to life, so the individual must begin to seek a livelihood, as in the example "Whoever wakes up in his sleep and wakes up in his waking lives a wise and healthy life." Sleeping Early is considered as immortal in terms of Morally was health, social and behavioral.

There is People different in biological rhythms and prefer morning or evening bites. People who prefer the morning pattern and those who are called "moon" prefer to wake up or go to bed early, because their best moments in the morning to do intellectual and physical activities, The owners of the evening style, who are described as "owl" feel better performing in the afternoon or late in the evening. This is a simple classification between rhythmic types and can be seen as a continuous series. (Randler 2011: 29)

The morning personality and the evening two types of personality first is the morning pattern, which is called Lark, who is awakening early and feel refreshed and dynamic and the second evening style and called Owl, he wakes up from sleep in the morning with difficulty and feel tired when waking early and remain awake until late at night. (Cavallera \& Giudici 2008: 4)

It is clear that the morning personality and personal evening differences in individual patterns of sleep and wake up to individuals and the best times of the day in which individuals feel their work, and study this character is a way to identify individual differences in individuals during the day and depends on the organization of sleep periods and Waking up are supposed to reflect the actual sleep patterns. (Anna - Karin 2005: 5)

The differences between the morning personality and the evening personality are evident in some aspects of the personality (such as emotions, behavior, and thinking), where students of the evening style face many pressures to achieve professional and academic compatibility because most universities begin earlier in the day, and work begins early of the day in most state institutions, making the process of waking up early in the morning and regular study is difficult. (Abd el- Moneim Hassib 2009: 175) (Muro et al., 2009: 38) 
The evening results also affect the academic performance, The results of the studies indicate that students of the evening style suffer from many problems of lack of attention and low level of academic achievement and thus a decrease in academic achievement. The study of Digdon \& Howell (2008) ,Besoluk (2011), Escrbano et al. (2012), Diaz Morales, \& Escribano, (2013), Sara Allam (2017), (Anna - Karin 2005: 119)

Through this the researcher believes that the low feeling of satisfaction with life has negative effects on students with an evening personality, so we need to design sports programs in particular and sports recreation programs in general, which works to develop a sense of satisfaction with life and the desire and the real desire to live, where this variable contains several attributes the most important qualities are altruism, optimism, expectation of good, self satisfaction, acceptance and respect .

The games promote social awareness, social interaction, confidence, self satisfaction and friendships. (Danny Wayne Pettry 2006: 37 - 41), and contribute activities and recreational games to protect students from boredom, anxiety, depression and psychological pressure, in which the student expresses himself and be friendships and cooperation and interaction with others, and improve his physical, mental, social and psychological, and achieve happiness and satisfaction Self esteem, confidence and trust, and adjusts its direction in such a way that life becomes bright and becomes brighter and more joyful. (Taha 2006: 17-26), (Tolba 2010: 44-46) (Lo; Chang \& Chang, 2009: 250-262), Titze (Merom; Rissel \& Bauman 2014: 485 - 490)

Improving the quality of life, feeling happy and relaxed, improving physical fitness, freedom from stress, tension and self-expression, making new friends or cooperating with others, self-satisfaction, self-assertion, And acquire knowledge and experience, problem solving, achievement, quality of life, development Personal health, mental, social and psychological. (Kraus 2015: 1-156)

The researcher believes that recreational games feel the students personal happiness, fun, love, reassurance and stability, And works to improve the sense of self strength , defense and assertion .and how to deal with problems, mental disorders, self awareness, social, a sense of confidence, safety and satisfaction with life, where the sense is the starting point to solve many of the psychological and social problems .
From the above it is clear to the researcher that students with an evening character need to help them to develop a sense of satisfaction with life and the extent of their personal acceptance of their past and present life and their interaction with aspects of the environment and their ability to agree with the problems they face.

And from here the idea of the research stems from the researcher's view that it is necessary to develop the recreational games program to develop a sense of satisfaction with the life of the evening personalities, as to the knowledge of the researcher no one of researchers has taken up this subject, which adds importance and need to conduct it.

\section{Research Objective:}

The aim of the research is to develop a sense of satisfaction with the life of the members of the evening personality through the recreational games program.

\section{Research Hypothesis:}

There are statistically significant differences between the mean pre and post measurements of the research sample in developing the feeling of satisfaction with the life of the members of the evening character for the benefit of remote measurement through the recreational games program.

\section{Research Procedure:}

\section{Research Methodology:}

The researcher used the experimental methodology with the design of one group and both pre and post measurements.

\section{Community and Sample Search:}

The research community represents the students of the fourth year at the Faculty of Physical Education - Tanta University, which is (200) students for the academic year 2016 - 2017.

The researcher chose the basic research sample in the deliberate manner of the research community, and reached (30) students of the evening personalities as shown table(1), the family status of the stable family, and the family income level is average (15\%) to implement the proposed program. The researcher confirmed the moderation of the research sample in the variables in question as shown in Table (1). 
Table (1)

Characterization of the sample in the basic variables in research to show the moderation of the data $(\mathrm{N}=30)$

\begin{tabular}{|c|c|c|c|c|c|c|c|}
\hline $\mathrm{N}$ & Variables & $\begin{array}{c}\text { unit } \\
\text { Measurement }\end{array}$ & Mean & Median & Standard deviation & Flattening & skews \\
\hline \multicolumn{8}{|c|}{ Growth rates : } \\
\hline 2 & Height & $\mathrm{cm}$ & 172.20 & 171.50 & 11.81 & 0.16 & 0.44 \\
\hline 3 & Weight & $\mathrm{Kg}$ & 76.10 & 75.00 & 14.26 & $0.98-$ & 1.01 \\
\hline \multicolumn{8}{|c|}{ Evening Personality Scale : } \\
\hline 1 & Knowledge side & Degree & 17.30 & 18.00 & 2.49 & $0.19-$ & $0.64-$ \\
\hline 2 & Emotional side & Degree & 18.00 & 18.00 & 2.69 & 0.58 & 0.84 \\
\hline 3 & Physical and skilled side & Degree & 19.47 & 20.00 & 1.80 & $0.81-$ & $0.23-$ \\
\hline 4 & Total score of the scale & Degree & 54.77 & 55.50 & 4.07 & $0.33-$ & $0.70-$ \\
\hline \multicolumn{8}{|c|}{ Develop a sense of satisfaction with life : } \\
\hline 2 & Social & Degree & 6.87 & 7.00 & 0.97 & 0.30 & 0.28 \\
\hline 3 & Tranquility & Degree & 9.37 & 9.00 & 1.85 & $0.28-$ & 0.47 \\
\hline 4 & Psychological stability & Degree & 4.10 & 4.00 & 1.03 & $0.50-$ & $0.78-$ \\
\hline 5 & Social assessment & Degree & 10.80 & 11.00 & 1.19 & $1.25-$ & $0.52-$ \\
\hline 6 & Contentment & Degree & 3.97 & 4.00 & 1.03 & $0.87-$ & $0.13-$ \\
\hline 7 & Total score of the scale & Degree & 45.41 & 46.00 & 3.89 & $1.06-$ & 0.11 \\
\hline
\end{tabular}

Table (1) shows the values of the skews coefficient and the flattening coefficient ranged between \pm 3 , which gives a direct indication of the absence of data from distribution defects unusual. And value of the mean of the evening personal measure 54.77 , and Develop a sense of satisfaction with life 45.41 .

\section{Data collection methods:}

(1) Morning-Evening Scale (Prepared by Sara Allam, 2017): The value at a significant level of $0.05=0.44$.

Table (2)

Believe the internal consistency between the phrase and the Dimensions and between the phrase and the total sum and the total sum For the evening profile

\begin{tabular}{|c|c|c|c|c|c|c|c|c|}
\hline \multicolumn{3}{|c}{ The first axis } & \multicolumn{3}{c|}{ The second axis } & \multicolumn{3}{c|}{ The third axis } \\
\hline $\mathrm{N}$ & $\begin{array}{c}\text { The phrase } \\
\text { with the axle }\end{array}$ & $\begin{array}{c}\text { The phrase with } \\
\text { the total }\end{array}$ & $\mathrm{N}$ & $\begin{array}{c}\text { The phrase } \\
\text { with the axle }\end{array}$ & $\begin{array}{c}\text { The phrase with } \\
\text { the total }\end{array}$ & $\mathrm{N}$ & $\begin{array}{c}\text { The phrase } \\
\text { with the axle }\end{array}$ & $\begin{array}{c}\text { The phrase } \\
\text { with the total }\end{array}$ \\
\hline 1 & 0.85 & 0.81 & 1 & 0.79 & 0.84 & 1 & 0.87 & 0.90 \\
\hline 2 & 0.89 & 0.86 & 2 & 0.84 & 0.91 & 2 & 0.73 & 0.77 \\
\hline 3 & 0.88 & 0.81 & 3 & 0.74 & 0.80 & 3 & 0.86 & 0.89 \\
\hline 4 & 0.82 & 0.91 & 4 & 0.83 & 0.91 & 4 & 0.77 & 0.81 \\
\hline 5 & 0.86 & 0.88 & 5 & 0.87 & 0.84 & 5 & 0.86 & 0.91 \\
\hline 6 & 0.83 & 0.87 & 6 & 0.84 & 0.87 & 6 & 0.87 & 0.79 \\
\hline 7 & 0.80 & 0.83 & 7 & 0.78 & 0.91 & 7 & 0.85 & 0.82 \\
\hline 8 & 0.86 & 0.90 & 8 & 0.84 & 0.78 & 8 & 0.86 & 0.81 \\
\hline 9 & 0.73 & 0.78 & 9 & 0.76 & 0.81 & 9 & 0.88 & 0.86 \\
\hline & & & & & & 10 & 0.83 & 0.79 \\
\hline
\end{tabular}


Table (2) shows the existence of a statistically significant correlation between the expression and the Dimensions and between the statement and the total sum and the total sum of the axes, which indicates the validity of the internal consistency of the evening personality scale at a significant level of 0.05 .

Table (3)

Half-interval and alpha coefficients to show the stability coefficient of the evening personal scale $(\mathrm{N}=20)$

\begin{tabular}{|c|c|c|c|c|}
\hline \multirow{2}{*}{$\mathrm{N}$} & Scale dimensions & \multicolumn{2}{|c|}{ Half-interval } & \multirow{2}{*}{ Cronbach's Alpha if Item Deleted } \\
\cline { 3 - 5 } & & Spearman - Brown & Getman & 0.863 \\
\hline 1 & Knowledge side & 0.854 & 0.758 & 0.876 \\
\hline 2 & Emotional side & 0.761 & 0.799 & 0.812 \\
\hline 3 & Physical and skilled side & 0.804 & 0.882 & 0.761 \\
\hline 4 & Total score & 0.864 & 0.852 \\
\hline
\end{tabular}

Table (3) shows the half-deflection test in the SpearmanBrown and Getman methods as well as the alpha coefficient (Cronbach ) to show the stability coefficient of

the three dimensions of the evening survey in addition to the total scale.

Table (4)

Analysis of dimensions of the evening profile $(\mathbf{N}=\mathbf{3 0})$

\begin{tabular}{|c|c|c|c|c|c|}
\hline $\mathrm{N}$ & Scale dimensions & mean & Standard deviation & Coefficient of variation & 14.41 \\
\hline 1 & Knowledge side & 17.30 & 2.49 & 14.95 \\
\hline 2 & Emotional side & 18.00 & 2.69 & 5.06 \\
\hline 3 & Physical and skilled side & 19.47 & 1.80 & 40.00 \\
\hline & Total score & 54.77 & 4.07 & 4.42 & 45.64 \\
\hline
\end{tabular}

Table (4) shows that the total measure of evening character has achieved a relative importance of $(45.64 \%)$, which indicates that these individuals belong to the style of the evening character.
(2) The measure of satisfaction with life (Prepared by: Magdy Mohamed Al-Desouky, 2013):

The researcher also found stability by means of the Spearman-Brown and Getman midterm testing, as well as the A.Cronbach coefficient, as shown in Table (5), (6).

Table (5)

Believe the internal consistency between the phrase and the Dimensions and between the phrase and the total sum of the dimensions For the development of a sense of satisfaction with life $(\mathbf{N}=\mathbf{2 0})$

\begin{tabular}{|c|c|c|c|c|c|c|c|c|c|c|c|c|c|c|c|c|c|}
\hline \multicolumn{3}{|c|}{ first axis } & \multicolumn{3}{|c|}{ second axis } & \multicolumn{3}{|c|}{ fifth axis } & \multicolumn{3}{|c|}{ fourth axis } & \multicolumn{3}{|c|}{ fifth axis } & \multicolumn{3}{|c|}{ sixth axis } \\
\hline $\mathrm{N}$ & $\begin{array}{l}\text { The } \\
\text { phrase } \\
\text { with } \\
\text { the } \\
\text { axle }\end{array}$ & $\begin{array}{l}\text { The } \\
\text { phrase } \\
\text { with } \\
\text { the } \\
\text { total }\end{array}$ & $\mathrm{N}$ & $\begin{array}{l}\text { The } \\
\text { phrase } \\
\text { with } \\
\text { the } \\
\text { axle }\end{array}$ & $\begin{array}{l}\text { The } \\
\text { phrase } \\
\text { with } \\
\text { the } \\
\text { total }\end{array}$ & $\mathrm{N}$ & $\begin{array}{l}\text { The } \\
\text { phrase } \\
\text { with } \\
\text { the } \\
\text { axle }\end{array}$ & $\begin{array}{l}\text { The } \\
\text { phrase } \\
\text { with } \\
\text { the } \\
\text { total }\end{array}$ & $\mathrm{N}$ & $\begin{array}{l}\text { The } \\
\text { phrase } \\
\text { with } \\
\text { the } \\
\text { axle }\end{array}$ & $\begin{array}{l}\text { The } \\
\text { phrase } \\
\text { with } \\
\text { the } \\
\text { total }\end{array}$ & $\mathrm{N}$ & $\begin{array}{l}\text { The } \\
\text { phrase } \\
\text { with } \\
\text { the } \\
\text { axle }\end{array}$ & $\begin{array}{l}\text { The } \\
\text { phrase } \\
\text { with } \\
\text { the } \\
\text { total }\end{array}$ & $\mathrm{N}$ & $\begin{array}{l}\text { The } \\
\text { phrase } \\
\text { with } \\
\text { the } \\
\text { axle }\end{array}$ & $\begin{array}{l}\text { The } \\
\text { phrase } \\
\text { with } \\
\text { the } \\
\text { total }\end{array}$ \\
\hline 1 & 0.79 & 0.86 & 1 & 0.78 & 0.82 & 1 & 0.80 & 0.86 & 1 & 0.74 & 0.79 & 1 & 0.67 & 0.73 & 1 & 0.71 & 0.82 \\
\hline 2 & 0.71 & 0.77 & 2 & 0.82 & 0.89 & 2 & 0.73 & 0.81 & 2 & 0.84 & 0.91 & 2 & 0.75 & 0.81 & 2 & 0.88 & 0.92 \\
\hline 3 & 0.74 & 0.80 & 3 & 0.76 & 0.81 & 3 & 0.79 & 0.82 & 3 & 0.72 & 0.83 & 3 & 0.86 & 0.90 & 3 & 0.79 & 0.83 \\
\hline 4 & 0.83 & 0.87 & 4 & 0.71 & 0.74 & 4 & 0.68 & 0.74 & & & & 4 & 0.82 & 0.85 & & & \\
\hline 5 & 0.76 & 0.84 & 5 & 0.75 & 0.83 & 5 & 0.73 & 0.81 & & & & 5 & 0.71 & 0.76 & & & \\
\hline 6 & 0.73 & 0.81 & & & & 6 & 0.81 & 0.89 & & & & 6 & 0.68 & 0.72 & & & \\
\hline 7 & 0.80 & 0.85 & & & & & & & & & & & & & & & \\
\hline \multicolumn{18}{|c|}{ Coefficient of correlation } \\
\hline & \multicolumn{2}{|c|}{ first axis } & & \multicolumn{2}{|c|}{ second axis } & & \multicolumn{2}{|c|}{ fifth axis } & & \multicolumn{2}{|c|}{ fourth axis } & & \multicolumn{2}{|c|}{ fifth axis } & & \multicolumn{2}{|c|}{ sixth axis } \\
\hline & \multicolumn{2}{|c|}{0.76} & & \multicolumn{2}{|c|}{0.81} & & \multicolumn{2}{|c|}{0.79} & & \multicolumn{2}{|c|}{0.84} & & \multicolumn{2}{|c|}{0.77} & & \multicolumn{2}{|c|}{0.82} \\
\hline
\end{tabular}

The value is at a significant level of $0.05=0.44$ 
Table (5) shows the existence of a statistically significant correlation between the expression and the Dimensions and between the expression and the total number of dimensions of the measure of development of feeling of satisfaction with life at a significant level of 0.05 .

Table (6)

Half-interval and Alpha factor to show the stability coefficient of the Measure of developing a sense of satisfaction with life $(N=20)$

\begin{tabular}{|c|c|c|c|c|}
\hline \multirow{2}{*}{$\mathrm{N}$} & & \multicolumn{2}{|c|}{ Half-interval } & \multirow{2}{*}{ Cronbach's Alpha if Item Deleted } \\
\cline { 2 - 4 } & Scale dimensions & Spearman - Brown & Getman & 0.775 \\
\hline 1 & The first dimension & 0.759 & 0.765 & 0.786 \\
\hline 2 & The second dimension & 0.824 & 0.806 & 0.758 \\
\hline 4 & The third dimension & 0.761 & 0.778 & 0.773 \\
\hline 5 & The fourth dimension & 0.787 & 0.732 & 0.712 \\
\hline 6 & The fifth dimension & 0.713 & 0.704 & 0.781 \\
\hline 7 & The sixth dimension & 0.689 & 0.793 & 0.773 \\
\hline
\end{tabular}

Table (6) shows the half-separation test in the SpearmanBrown and Getman methods as well as the AlphaCronbach coefficient to show the stability coefficient of the six dimensions of the measure of development of satisfaction with life as well as the total scale.

\section{(3) Recreational games program (preparation by the researcher):}

The researcher prepared and selected a range of activities and recreational games aimed at achieving a sense of personal happiness and pleasure and satisfaction, and satisfaction and coexistence with peers and accept others, self-confidence and self-reliance, security and tranquility, and face the burdens of life, tolerance and fun with others, The experts were unanimous (9) experts on the importance of those activities and games proposed for the personal evening, where the percentage of their views ranged between $(88.89 \%)$ as the smallest percentage , (100\%) as the largest proportion, and distributed as units for the recreational games program.

\section{The goal of the recreational games program:}

Develop a sense of satisfaction with the life of the people of the evening personality and achieve personal happiness for them.

\section{The program Foundations:}

- The use of games and recreational activities characterized by marketing, expression and simplicity of performance.

- The program is compatible with the Properties and attributes of students.
- Accountability the psychological atmosphere of the sample during application.

- Accountability the breaks between games.

- Accountability the factors of safety and safety so that the selected aspects of the level of health and the observation of physical fatigue appear on the students.

- The content of the program should be commensurate with the objectives for which it was developed (to develop a sense of satisfaction with life for the students of the Faculty of Physical Education from the members of the evening personality).

- Using Means and tools of various shapes, color and size.

\section{Program Content:}

The program contains the following parts:

The preparatory part: aims to prepare the students physically and psychologically and introduce the spirit of fun and pleasure and enthusiasm for active participation in the active units of the program, and is a set of activities and recreational games and the time of this part (10)minute.

The main part: A group of activities and recreational games that are fun and joy and achieve personal happiness that is consistent with the goal of unity and the purpose of the program (the development of a sense of satisfaction with the lives of people with the personality of morning and evening), and the time of this part (40) minute. 
The final part: This part aims to calm the body and return to the natural state and renew energy and the introduction of fun and pleasure and happiness, which is a collection of games and recreational activities, and the time of this part (10) minute.

The researcher prepared the program in its preliminary form and presented it to experts ( 9 experts) from experts in recreation, psychology and mental health. They pointed to the cancellation of a small number of games and the modification of some of them.

The program includes (32) units applied over a period of about two months at (4) units per week for (8) weeks, and the researcher applied in a direct way and shows the role of the researcher is designed for the environment in which the games and recreational activities will encourage the performance of individual and collective Guide and guide the student from activity to another and rely on themselves to challenge the difficulties in the light of their abilities.

The researcher conducted the second exploratory study to apply some units of the program to determine the suitability of the research sample during the period from
Tuesday $21 / 2 / 2017$ to Thursday $23 / 2 / 2017$, This study resulted in achieving its goal.

\section{Research Measurements:}

The researcher carried out the pre measurement of the satisfaction of life on the basic research sample on Sunday 26/2/2017 and on Monday 27/2/2017. The recreational games program was implemented over a period of (8) consecutive weeks from Sunday 5/3/2017 to Thursday $27 / 4 / 2017$, and then the post measurement of the dimension of satisfaction of life on the basic research sample was conducted on Tuesday 2/5/2017 and on Wednesday 3/5/2017.

\section{Statistical Processes:}

The researcher used the statistical package program SPSS to process the data statistically, using the following statistical methods (mean, median, standard deviation, flattening, skews factor, correlation coefficient, alpha Cronbach coefficient, $\mathrm{T}$ test, improvement ratio).

\section{The Results and Discuss:}

\section{The Results:}

Table (7)

Significance of differences between pre and post measurement

The research group has developed a sense of satisfaction with the life in question $(N=30)$

\begin{tabular}{|c|c|c|c|c|c|c|c|c|c|}
\hline \multirow[t]{2}{*}{$\mathrm{N}$} & \multirow[t]{2}{*}{ Scale dimensions } & \multicolumn{2}{|c|}{$\begin{array}{c}\text { Pre } \\
\text { measure }\end{array}$} & \multicolumn{2}{|c|}{$\begin{array}{c}\text { Post } \\
\text { measure }\end{array}$} & \multirow{2}{*}{$\begin{array}{l}\text { Average } \\
\text { differences }\end{array}$} & \multirow{2}{*}{$\begin{array}{l}\text { Standard error of } \\
\text { mean }\end{array}$} & \multirow{2}{*}{$\begin{array}{c}\mathrm{t} \\
\text { Value }\end{array}$} & \multirow{2}{*}{$\begin{array}{c}\text { Rate of } \\
\text { improvement } \%\end{array}$} \\
\hline & & M & $\pm \mathrm{Z}$ & M & $\pm \mathrm{Z}$ & & & & \\
\hline 1 & Happiness & 10.30 & 1.42 & 19.03 & 2.09 & 8.73 & 0.295 & 29.57 & 84.79 \\
\hline 2 & Social & 6.87 & 0.97 & 12.50 & 1.25 & 5.63 & 0.148 & 38.15 & 82.04 \\
\hline 3 & Tranquility & 9.37 & 1.85 & 13.60 & 1.94 & 4.23 & 0.141 & 29.96 & 45.20 \\
\hline 4 & Psychological stability & 4.10 & 1.03 & 7.20 & 1.06 & 3.10 & 0.074 & 42.18 & 75.61 \\
\hline 5 & Social assessment & 10.80 & 1.19 & 17.33 & 1.32 & 6.53 & 0.142 & 46.04 & 60.46 \\
\hline 6 & Contentment & 3.97 & 1.03 & 7.27 & 1.17 & 3.30 & 0.085 & 38.78 & 83.19 \\
\hline 7 & $\begin{array}{l}\text { The total degree of the measure of } \\
\text { satisfaction with life }\end{array}$ & 45.41 & 3.88 & 76.93 & 5.01 & 31.52 & 0.50 & 62.15 & 69.41 \\
\hline
\end{tabular}

T value at a significant level of $0.05=1.70$

Table (7) shows that there are statistically significant differences at the mean level of 0.05 between the average of the pre and post measurement the in the research sample in developing the feeling of satisfaction with life, The $(\mathrm{T})$ value was calculated in all dimensions of the measure of satisfaction of life for the people of the morning-evening personality was (62.15), which is higher than the value of $(\mathrm{T})$ table for the benefit of post measurement.

\section{Results Discussion:}

Table (7) shows that rate of improvement of the sample of research in the development of a sense of satisfaction with life in the total score of the measure of satisfaction of life for the evening personalities was (69.41), through the recreational games program, which shows the positive impact of the recreational games program in the development of feeling Satisfied with life for those with an evening personality, 
The researcher attributed the improvement to the content of the recreational games program in a manner suitable to the characteristics and needs of the evening personality of diversity and versatility in the use of games and recreational activities as well as their flexibility and their ease, in addition to the diversity in the use of different methods in shape, size and color, and use concrete models.

The results indicate that students with an evening personality feel a decline in the future direction because they do not think about their future and tend to delay and decision, and commit to a lot of psychological pressure as a result of procrastination in some life tasks and prefer to delay the daily activities and academic to after noon or night, wasting time and do not accomplish Their tasks are on time and therefore do not realize the value of time , This is consistent with the results of Diaz-Morales study. (Diaz-Morales, J. 2008: 228-240)

Also The results indicate that Students with an evening personality are also more prone to mental and behavioral disorders (Ranfle 2008: 191-196), and tend to negative social behavior and thus have a low satisfaction with life (Bae et al., 2010: 646-651). It is clear that the evening character is depressed and this result is in the middle stage of life more clear. (Kim et al., 2010: 159 - 164)

The researcher agrees with the findings university performance is worse among the students of the evening, where it is associated with the optimal sleep period with positive performance in the university where the students with evening personality sleep short periods, and the conversion of students time from morning to evening, making it difficult to agree with the university schedule in the morning. (Escribsno, et. A. 2012: 409 - 413),(Preckel, et al., 2013: 114-134)

And the exercise of recreational activity is important in the extent of its contribution to the improvement of the individual's physical, mental and psychological as well as raise physical efficiency and morale and a sense of safety and tranquility and the efficiency of vital devices. (Tolba: 11)(Stubinger 2015: 4, 5, 81, 95 )

The recreational games are one of the most important and successful educational methods and one of the most important means to help students grow a balanced growth of all physical, mental, social and psychological aspects.

It is a necessity of everyday life that makes the student live a productive and productive life that contributes to the development of a sense of satisfaction with life And social adjustment within the area in which he lives where he feels the importance and value in life, and thus verify the validity of the search.

\section{Research Conclusions:}

The recreational games program has a positive effect on the development of a sense of satisfaction with the life of those with an evening personality.

\section{Research Recommendations:}

1- Activate the program of recreational games proposed and applied at a broader level in the areas of professional working at night (with evening personality).

2- Develop the religious awareness of young people by acquiring the correct sleep and awakening habits recommended by the heavenly religions.

3- Activating the role of the family in controlling the behavior of children and observing their actions, and the continuity of their guidance.

4- Follow some methods and recreational teams and recreation, such as prayer, meditation and relaxation to alleviate the disorders and psychological problems and severity.

\section{References}

1- Al-Desouki, Magdy Mohamed (2013): a measure of satisfaction with life, instruction manual, the Anglo Egyptian Library.

2- Hassib, Abdel-Moneim Abdulla (2009): Morning Evening Personality and its Relationship to Strategies of Dealing with Stress and the Major Factors of Personality and Ability to Bear Frustration, Egyptian Association of Psychological Studies, p. 64 (19), pp. 169-217.

3- Tolba, Mahmoud Ismail (2010): the psychology of recreation and leisure, Islamia Graphic, Cairo.

4- Taha, Taha Abdul Rahim (2006): entrance to recreation, Dar Al Wafa, Alexandria.

5- Allam, Sara Al-Mahdy (2017): Morning-evening personality and its relation to some cognitive and mood variables in secondary students, unpublished master thesis, Faculty of Education, Department of Mental Health, Tanta University.

6- Ann - Karin Andershed (2005). Insync with adolescence : The Role of Morning ness - Evening ness in Development, Springer Library of Congress Cataloging in - Publication Data. 
7- Bae, S; Park, J; Lee, Y; Cho, I; Kim, J; Koh, S; Kim, S. \& Cho, S. (2010). Gender difference in the association between adult attention deficit hyperactivity disorder symptoms and morningness - Eveningness. Psychiatry and Clinical Neurosciences, Vol. 64, P. 649 - 651.

8- Besoluk, S. (2011). Morning ness - evening ness preferences and university entrance examination scores of high school students, Personality and individual differences, Vol. 50, P. 248-252.

9- Cavallera, GM \& Giudici, S. (2008). Morning ness and evening ness personality: A surver in literature from 1995 up 11 - 2006, Personality and Individual Differences, Vol. 44, P. 3-21.

10- Danny Wayne Pettry (2006). Building social skills through activities, certified Therapeutic Recreation Specialist, United States of America.

11- Diaz-Morales, J. \& Escribano, C. (2013). Predicing school achievement : The role of inductive reasoning, sleep length and morning ness - evening ness, Personality and Individual Differences, Vol. 55, P. 106-111.

12- Diaz-Morales, J. Sanchez-Lopez. (2008). Indecision and Avoidant procrastination : The Role of Morningness. Eveningness and Time Perspective in Chronic Delay Life Styles. General Psychology, Vol. 135 (3), P. 228 - 240.

13- Digdon, N. A. \& Howell, A. S. (2008). college students who have an evening ness preferens sreport lower self - control and greater procrastination, Department of Psychology, Grant MacCwan College, Canada, Vol. 25 (6), P. 1029 - 1046.

14- Escribano, C.; Diaz - Morales, J.; Delgado, P. \& Collado, M. D. (2012). Morning ness - evening ness and school performance among Spanish adolescents : further evidence, Learning and Individual Differences, Vol. 22, P. $409-413$.

15- Georg Stuebinger (2015). Sports and Exercise Training as therapy in cancer, Springer, Library of Congress Control, Graz, Austria, 2015.

16- Hong, X., \& Janet, B. (2008). The effect of perceived health status on patient satis faction, Value in Health, 11 (4), 719 - 725. Doi : 101111/j:1524-4733.2007.002,4.x
17- Kim, S. J; Lee, Y. J; Kim, H; Cho, I, H; Lee, D. Y. \& Cho S. J. (2010). Age as a moderator of the association between depressive symptoms and morningness eveningness. Psychosomatic Research, Vol. 68, P. 159 164.

18- Kraus, R. (2015). Recreation and leisure in modern society, 10th Edition, Jones and Bartlett Publishers, Canada.

19- Lo; Chang \& Chang, (2009). Research on Recreational sports instruction using an expert system, Springer Verlag Berlin Heidelbery, 250-262.

20- Muro, A.; Goma, M. \& Adan, A. (2009). Morning ness, evening ness, sex, and the alternative five factor model of personality, Department of Health Psychology, Universital Autonoma de Barcelona, Spain, Vol. 26 (6), P. 35-48.

21- Prekel, F; Lipnevich, A; Boehme, K; Brand, L; Georgi, K; Konen, T; Mursin, K; Roberts, R. (2013). Morningness - eveningness and educational outcomes : the larkhas an advantage over the owl at high school. British Journal of Educational Psychology, Vol. 83 (1), P. $114-134$.

22- Randler, C. (2008). Morningness - Eveningness sleep - wakw variables and biyfice personality factors. Personality and Individual Differences, Vol. 45, P. 191 196.

23- Randler, C. (2011). Associa on between morningness - eveningness and mental, physical health in adolescent, Institute of Natural Science and Technology, University of Education Heideberg, Germany, Vol. 16 (1), P. 29-38.

24- Richard Kraus ( 2015 ). Recreation and leisure in modern society, 10th Edition, Jones and Bartlett Publishers, Canada.

25- Titze; Merom; Rissel \& Bauman, (2014). Epidemiology of cycling for exercise, recreation of sport in Australia and its contribution to health enhancing physical activity, Journal of Science and Medicine in Sport, Vol. 17, P. 485 - 490. 